\title{
BREAST FEEDING AND WEIGHT LOSS PATTERN IN TERM NEONATES DURING FIRST 72 HOURS OF LIFE: A CROSS SECTIONAL OBSERVATIONAL STUDY
}

\author{
Badri Kumar Gupta, ${ }^{1}$ Binod Kumar Gupta, ${ }^{1}$ Raju Kaphle, ${ }^{1}$ Sandeep Shrestha, ${ }^{1}$ Nagendra Chaudhary ${ }^{1}$
}

\section{ABSTRACT}

\section{INTRODUCTION}

Healthy, full term, exclusively breastfed infants are expected to lose weight in the first days following birth. There are conflicting opinions about what constitutes a normal neonatal weight loss. This study was conducted to establish the reference weight loss pattern in exclusively breastfed neonates.

\section{MATERIAL AND METHODS}

A cross sectional observational study was conducted at a tertiary care hospital of western Nepal for a period of 12 months. All babies delivered were recruited. Newborns with birthweight of $>2500$ grams without any congenital anomalies and Apgar score $>7 / 10$ were finally included for analysis. Breast feeding was started as soon as possible and all newborns were fed within 6 hours of life. If breast feeding was not possible within first 2 hours of life, expressed breast milk (EBM) or formula feeding was initiated as recommended. Data was analyzed showing distribution and frequency of various parameters like initiation of breastfeeding, weight of babies at different time intervals and weight loss patterns.

\section{RESULTS}

Out of 1000 babies subjected to analysis, majority were males $(n=517,51.7 \%)$. The average time of initiation of breast feeding was less than 6 hours. The weight loss pattern in babies was $7.1 \%$ at 72 hours of life.

\section{CONCLUSION}

Breast feeding was initiated as soon as possible in all healthy term neonates. The average weight loss pattern in all term healthy newborns were almost similar.

KEY WORDS Breast feeding, weight loss pattern, initiation of breast feeding

1. Department of Pediatrics, Universal College of Medical Sciences, Bhairahawa, Nepal

DOI: https://doi.org/10.3126/jucms.v6i2.22467

For Correspondence

Dr. Badri Kumar Gupta

Department of Pediatrics

Universal College of Medical Sciences

Bhairahawa, Nepal

Email: drbadrikrgupta@gmail.com 


\section{INTRODUCTION}

Neonatal weight loss is recognized universally but the weight loss pattern is yet poorly understood. ${ }^{1}$ The consensus on average normal weight loss and lower limit of safe weight loss is limited. Inadequately breast fed infants can undergo dehydration and hyperbilirubinemia leading to life threatening conditions like hypernatremic dehydration and kernicterus. $^{2,3}$

Neonates receive only small amount of fluid in the first days following birth and they tend to lose weight before they begin to gain weight. Excessive weight loss or inadequate weight gain can be indication of low milk production or insufficient milk transfer. Seasonal variation also plays an important role in weight loss pattern of newborns. Therefore, weight loss pattern needs special attention in low and middle income countries (LMICs) like Nepal where majority of hospital wards are not having humidity and air conditioning control.

Weight monitoring, therefore, can be an important tool to assess the adequacy of feeding and the need for supplementation (formula feeds or expressed breast milk. This study was thus conducted to assess the weight loss pattern in exclusively breast fed healthy teem infants and to assess the mean duration of initiation of breast feeding.

\section{MATERIAL AND METHODS}

A cross sectional observational study was conducted at a tertiary care hospital of western Nepal for a period of 12 months. All babies delivered were recruited. Newborns with birth weight of $>2500$ grams without any congenital anomalies and Apgar score $>7 / 10$ were finally included for analysis. Preterm babies, low birth weight babies, babies with congenital anomalies, twin pregnancies, asphyxiated babies, formula fed babies and those born to chronic maternal diseases were excluded from the analysis. Breast feeding was started as soon as possible and all newborns were fed within 6 hours of life. Descriptive analysis of variables were done in the form of mean and percentage.

Exclusive breast feeding was defined as per WHO definition (breast milk with no other foods or liquids including water, with the exception of medicines, vitamins or minerals). Term gestation was defined as a gestation of $>259$ days $\left(36^{6 / 7}\right.$ weeks). Data analysis was done by SPSS-version 21. P values of $<0.05$ was considered significant.

\section{RESULTS}

Out of total 1050 recruited babies, 1000 babies fulfilled the inclusion criteria and were subjected to analysis. The mean birth weight of babies was 2938.80 gm with a standard deviation of $276.29 \mathrm{gm}$. Male babies were slightly higher than females $(51.7 \%$ versus $48.3 \%) .74 \%(n=740)$ babies were delivered by normal vaginal delivery (NVD) and rest $(26 \%$, $\mathrm{n}=260)$ by cesarean section (Table 1$) .76 .9 \%(\mathrm{n}=769)$ babies were put on breast feeding within 2 hours of life (Table 2). Majority of babies delivered by NVD were put on breast milk within 2 hours of life whereas those babies delivered by cesarean section were breast fed at 2-4 hours of life.

The mean birth weight of babies at birth, 24 hours, 48 hours, and 72 hours were $2938.80 \mathrm{gm}, 2857.98 \mathrm{gm}, 2806.55 \mathrm{gm}$ and 2730.14 gm respectively with mean weight loss of $81 \mathrm{gm}$, $132.2 \mathrm{gm}$ and $208.65 \mathrm{gm}$ at $24 \mathrm{hrs}, 48 \mathrm{hrs}$ and $72 \mathrm{hrs}$ respectively (Table 3 ). The average percentage of weight loss at 24 hours, 48 hours and 72 hours was $2.75,4.5$ and 7.1 respectively. The cumulative percentage of weight loss from birth to 72 hours was $7.1 \%$.

\section{Table 1. Baseline characteristics}

\begin{tabular}{|l|l|}
\hline Variables & \\
\hline Age of mothers in years (mean/SD) & $25.4(3.9)$ \\
\hline Mode of delivery, n (\%) & $740(74)$ \\
NVD & $260(26)$ \\
LSCS & \\
\hline Sex, n (\%) & $517(51.7)$ \\
Male & $483(48.3)$ \\
Female & \\
\hline
\end{tabular}

Table 2. Initiation of breastfeeding at different intervals after birth $(n=1000)$

\begin{tabular}{|l|l|l|}
\hline Time & Number (n) & Percentage (\%) \\
\hline$<1$ hr & 473 & 47.3 \\
$1-2$ hrs & 296 & 29.6 \\
$2-3$ hrs & 183 & 18.3 \\
$3-4$ hrs & 28 & 2.8 \\
$4-5$ hrs & 18 & 1.8 \\
$5-6$ hrs & 2 & 0.2 \\
\hline
\end{tabular}

Table 3. Weight of babies at different time intervals after birth

\begin{tabular}{|l|l|l|l|}
\hline Time interval & Mean weight (gm) & $\begin{array}{l}\text { Mean weight loss } \\
\text { (gm) from birth }\end{array}$ & $\begin{array}{l}\text { \% weight loss } \\
\text { from birth }\end{array}$ \\
\hline At birth $(\mathrm{n}=1000)$ & 2938.80 & - & - \\
\hline At 24 hours( $(\mathrm{n}=999)$ & 2857.98 & 81 & 2.75 \\
\hline At 48 hours( $(\mathrm{n}=999)$ & 2806.55 & 132.2 & 4.5 \\
\hline At 72 hours( $(\mathrm{n}=999)$ & 2730.14 & 208.65 & 7.1 \\
\hline
\end{tabular}




\section{DISCUSSION}

Early initiation of breast feeding within one hour of birth is an important component of essential new born care..$^{5}$ A recent meta-analysis ${ }^{2}$ showed that initiation of breast feeding within first 24 hours of birth was significantly associated with reduction in all-cause neonatal mortality, low birth weight related neonatal mortality and infection related neonatal mortality among all live births. ${ }^{6}$ Child mortality has decreased significantly in Nepal due to universal adoption of breast feeding .

The present study suggests that majority (47.3\%) of newborns were breast fed within one hour of life whereas more than $3 / 4^{\text {th }}$ of babies received feeding within 2 hours of life. The finding is comparable to the Nepal Demographic and Health Survey conducted in 2011 (45\%) but much lower than that reported for the Kaski district (67\%) in central Nepal and higher than that reported by the 2006 Nepal Demographic and Health Survey $(35.4 \%){ }^{8,9}$

Our finding is higher than those reported from Bangladesh $(24 \%)$ and India (36.4\%) but lower than that of Sri Lanka $(83.3 \%){ }^{10-12}$

Such variation in the rates of early initiation within Nepal and within the South Asian countries is likely due to differences in the geography, ethnicity, culture, education of mothers and socioeconomic status. ${ }^{13}$

A study conducted by Adhikari et $\mathrm{al}^{13}$ found that $66.4 \%$ of babies were breast fed within the first hour which was more than our study. They also found that mothers who delivered in a health facility and whose children were large at birth were more likely to initiate breast feeding within the first hour of child birth. In the present study, majority of babies who were breast fed within one hour were delivered by normal vaginal delivery whereas those who were breast fed at 2-4 hours were delivered by cesarean section.

A study conducted recently (2015) in western $\mathrm{Nepal}^{14}$ suggested that mothers who were assisted by traditional attendants during childbirth, delivered by caesarean section, from ethnically disadvantaged families and those who delivered low birth weight infants were less likely to initiate breast feeding early whereas mothers who were from the poorest families and did not introduce prelacteal feeds to their infants were more likely to initiate breast feeding within the first hour.

This suggests that cesarean delivery prolongs breast feeding. The reason may be due to the time taken during the operative procedure, maternal anesthesia, pain and stress. ${ }^{11}$
The average weight loss from birth to 72 hours of life in the present study was $7.1 \%$. Various studies have reported the average weight loss pattern ranging from $5-10 \%$ during the first 72 hours. A systematic review of 11 studies demonstrating early weight loss patterns showed a mean loss of about $6 \%$.

Martens and Romphf determined exclusively breastfed babies lost a mean of $5.49 \%$ and supplemented breastfed babies lost an average of $5.52 \%$ in hospital which was less than the present study. ${ }^{16}$

In a study conducted by Cross land et al, it was observed that the average weight loss in newborns was $6.4 \%$ and the maximum weight loss was observed in the third day. ${ }^{17}$ In the present study also, the maximum weight loss was observed at 72 hours of life.

\section{CONCLUSION}

This study demonstrates that early breast feeding initiation is simple intervention that has the potential to significantly improve the neonatal outcomes and should be universally recommended. The average time of initiation of breast feeding in new born in UCMS TH was before 12 hours. The average weight loss was $7.1 \%$ at 72 hours of life.

\section{CONFLICT OF INTERESTS None}

\section{ACKNOWLEDGEMENTS}

The authors acknowledge the administration of UCMS-TH for providing necessary support during the study.

\section{REFERENCES}

1. Shroff R, Hignett R, Pierce C, Marks S, van't Hoff W. Life threatening hypernatraemic dehydration in breastfed babies. Arch Dis Child. 2006;91:1025-1026.

2. Chen YJ, Chen WC, Chen CM. Risk factors for hyperbilirubinemia in breastfed term neonates. Eur J Pediatr. 2012; 171:167-171.

3. Gourley GR. Breast-feeding, neonatal jaundice and kernicterus. Semin Neonatol. 2002; 7:135-141.

4. Lemons JA, Lockwood CJ. Guidelines for Perinatal Care. 6th ed. Atlanta, GA: American Academy of Pediatrics and The American College of Obstetricians and Gynecologists; 2007.

5. Bhutta, Z.A.; Das, J.K.; Bahl, R.; Lawn, J.E.; Salam, R.A.; Paul, V.K.; Sankar, M.J.; Blencowe, H.; Rizvi, A.; Chou, V.B. Can available interventions end preventable deaths in mothers, newborn babies, and stillbirths, and at what cost? Lancet 2014, $384,347-370$. 
6. Debes AK, Kohli A, Walker N, Edmond K, Mullany LC. Time to initiation of breastfeeding and neonatal mortality and morbidity: a systematic review. BMC Public Health. 2013;13 Suppl3:S19.

7. Darmstadt GL, Kinney MV, Chopra M, Cousens S, Kak L, Paul VK, et al. Who has been caring for the baby? Lancet Lond Engl. 2014 Jul 12;384(9938):174-88

8. Karkee, R.; Lee, A.H.; Khanal, V.; Binns, C.W. Initiation of breastfeeding and factors associated with prelacteal feeds in central Nepal. J. Hum. Lact. 2014, 30, 353-357.

9. Nepal Demographic and Health Survey 2006; Ministry of Health and Population: Kathmandu, Nepal; New ERA: Kathmandu, Nepal; Macro International Inc.: Calverton, MD, USA, 2007.

10. Haider R, Rasheed S, Sanghvi TG, Hassan N, Pachon H, Islam $\mathrm{S}$, et al. Breastfeeding in infancy: identifying the programrelevant issues in Bangladesh. Int Breastfeed J. 2010 Nov 30;5:21.

11. Patel, A.; Banerjee, A.; Kaletwad, A. Factors associated with prelacteal feeding and timely initiation of breastfeeding in hospital-delivered infants in India. J. Hum. Lact. 2013, 29, 572-578.

12. Senarath, U.; Siriwardena, I.; Godakandage, S.S.P.; Jayawickrama, H.; Fernando, D.N.; Dibley, M.J. Determinants of breastfeeding practices: An analysis of the Sri Lanka demographic and health survey 20062007. Matern. Child Nutr. 2012, 8, 315-329.
13. Adhikari M, Khanal V, Karkee R, Gavidia T. Factors associated with early initiation of breastfeeding among Nepalese mothers: further analysis of Nepal Demographic and Health Survey, 2011. International breastfeeding journal. 2014 Dec;9(1):21.

14. Khanal V, Scott JA, Lee AH, Karkee R, Binns CW. Factors associated with early initiation of breastfeeding in Western Nepal. International journal of environmental research and public health. 2015 Aug 14;12(8):9562-74.

15. Noel-Weiss J, Courant G, Woodend AK: Physiological weight loss in the breastfed neonate: a systematic review. Open Med 2008, 2:E11-22.

16. Martens PJ, Romphf L: Factors associated with newborn inhospital weight loss: comparisons by feeding method, demographics, and birthing procedures. J Hum Lact 2007, 23:233-241.

17. Crossland DS, Richmond S, Hudson M, Smith K, Abu-Harb M: Weight change in the term baby in the first 2 weeks of life. Acta Paediatr 2008, 97:425-429. 